\title{
Community-University Research Partnerships: Reflections on the Canadian Social Economy Experience
}

Peter V Hall \& Ian MacPherson (eds), University of Victoria, Victoria, BC, 2011, 259 pages

\author{
Marilyn Krogh
}

Gateways: International Journal of Community Research and Engagement Vol 6 (2013): 228-30 (C) UTSePress and the author

ISSN 1836-3393
During the last months of the liberal federal administration of Paul Martin in Canada (2003-2006), after a sustained lobbying campaign led by Quebec's Chantier de l'economie sociale and the Canadian Community Economic Development Network (CCED Network), funds were allocated to support the social economy sector of Canada, and a call was issued for research proposals on the social economy 'conducted by academic researchers in partnership with community based organizations'.

While the subsequent administration cancelled the general program everywhere except in Quebec, it retained the $\$ 15$ million research program, which was modelled on the existing Community University Research Alliance (CURA), funded by the Social Science and Humanities Research Council of Canada (SSHRC). Through a peer review process, SSHRC selected and funded six regional nodes and one national hub to pursue this research agenda from 2006 to 2012. This unprecedented level of resources for a pan-Canadian exploration of the social economy, known as Canadian Social Economy Research Partnerships (CSERP), resulted in almost 400 studies, involving 16 universities and over 140 community-based organisations.

This volume, Community-university research partnerships: Reflections on the Canadian social economy experience, describes the organisation of this large research effort. It provides context for chapters submitted by the hub and nodes, and concludes with directions for the future. A second volume, Assembling understandings, summarises the research findings across all the nodes. The third volume is Canadian public policy and the social economy. All three are available as free e-books at the website: http://socialeconomyhub.ca.

In this research, the social economy included not only the voluntary non-profit sector, as Americans might define it, but also cooperatives, social enterprises and informal, emerging efforts. Four of the node principal investigators knew each other from prior membership in a professional association for studying cooperatives.

The national hub for this research was located at the University of Victoria and co-directed by Ian McPherson, of the 
university, and Robert Downing, of the CCED Network. The leadership of each node was also a partnership between an academic institution and at least one community organisation. Five of the six academic institutions were universities, but one was Yukon College, which had never hosted a research project like this before. Sometimes the community organisations were apex associations, and sometimes they were looser networks. While the academic partner was typically the home institution, in the node for British Columbia and Alberta, the community partner took on that role.

Each node developed its own style of governance. The Atlantic node, the Northern Ontario, Manitoba and Saskatchewan node, and the British Columbia and Alberta node were decentralised, with an emphasis on local engagement. On the other hand, the Southern Ontario and Quebec nodes were more centralised, with more emphasis on policy dissemination. Each node, in turn, hosted from 25 to 80 collaborative projects over five or six years. All projects had to follow SSHRC guidelines for ethics and accounting, and all the nodes completed both mid-term and final evaluations.

In each node, there was only one full-time staff person dedicated to the research projects - the coordinator. All the coordinators had advanced degrees and stayed for five or six years, and took on a full range of responsibilities, although SSHRC considered them to be only administrative staff. In Chapter 10, they make the case for SSHRC to compensate this 'pracademic' role in the future.

While this volume focuses on process, each chapter submitted by a node lists their projects, and some tantalising hints about them emerge in the narratives. For instance, through the Northern Saskatchewan Trapper Association Cooperative, older and younger people reconnected with each other and 'all relations' (the animate in the land, animals and spirit world). In northern Ontario, the Coalition for Algoma Passenger Trains, resisted reductions in service on a small regional line, and found ways to diversify services and increase appreciation for the railroad's cultural significance. The most common projects involve mapping the social economy, social enterprises, cooperatives, indigenous people, organisational capacity, and public policy.

Chapter 3, submitted by the Atlantic node, analyses their decentralised internal functioning, and Chapter 4, submitted by the Quebec node, provides a straightforward checklist and graphic for evaluating the research partnership process. Chapter 8 , from the node led by the Canadian Centre for Community Renewal, describes functioning as a research base without the infrastructure of a university. Chapter 9 highlights some issues accentuated in the far north: the slow research permit process, the high cost of travel and, most importantly, a history of being treated as research subjects, not agents. 
Other chapters discuss familiar themes, such as the importance of attending to long-term relationships, not just tasks, as well as the true co-determination and implementation of projects. They also discuss familiar difficulties: the different standards of accountability, timelines, and financial support for academic and community-based researchers. They note, however, that the divide is more institutional than personal. Many academics have volunteered or lived in the community, and many community leaders have academic training. All the contributors stress the need for the SSRHC to fund community-based researchers in ways more comparable to academics.

Although the funding for this pan-Canadian effort has ended, some of the partnerships are continuing, or morphing into new forms. One outcome is the founding of the Association of Non-Profit and Social Economy Research (ANSER) and their online journal, ANSER-J, which is similar to Gateways. SSHRC guidelines have been modified to vet the quality of potential partnerships and to allow projects to evolve over time. Moreover, all three of Canada's research councils now have funding for universitycommunity partnerships.

This book will most interest people who would like to organise a similar effort, as well as readers who would like an introduction to this research in Canada, since it provides leads to many people, universities and organisations. Given the ascendency of neo-liberalism in Canada and elsewhere, MacPherson and Toye write (p. 38), 'The Social Economy is not the total answer to the pressures and possibilities that confront our times, but it offers strengths and resources that can be most useful - that it would be foolish not to explore seriously'. 